\title{
$\beta$-Adrenoceptor Blockers Increase Cardiac Sympathetic Innervation by Inhibiting Autoreceptor Suppression of Axon Growth
}

\author{
Gwenaëlle L. Clarke, Aritra Bhattacherjee, Sarah E. Tague, Wohaib Hasan, and Peter G. Smith \\ Department of Molecular and Integrative Physiology, and Kansas Intellectual and Developmental Disabilities Research Center, University of Kansas \\ Medical Center, Kansas City, Kansas 66160
}

\begin{abstract}
$\beta$-Adrenoceptor antagonists are used widely to reduce cardiovascular sympathetic tone, but withdrawal is accompanied by sympathetic hyperactivity. Receptor supersensitivity accounts for some but not all aspects of this withdrawal syndrome. Therefore, we investigated effects of $\beta$-blockers on sympathetic innervation. Rats received infusions of adrenergic receptor blockers or saline for 1 week. The nonselective $\beta$-blocker propranolol and the $\beta_{1}$-antagonist metoprolol both increased myocardial sympathetic axon density. At $2 \mathrm{~d}$ after propranolol discontinuation, $\beta$-receptor sensitivity and responsiveness to isoproterenol were similar to controls. However, tyramineinduced mobilization of norepinephrine stores produced elevated ventricular contractility consistent with enhanced sympathetic neuroeffector properties. In addition, rats undergoing discontinuation showed exaggerated increases in mean arterial pressure in response to air puff or noise startle. In sympathetic neuronal cell cultures, both propranolol and metoprolol increased axon outgrowth but the $\beta_{2}$-blocker ICI 118551 did not. Norepinephrine synthesis suppression by $\alpha$-methyl- $p$-tyrosine also increased sprouting and concurrent dobutamine administration reduced it, confirming that locally synthesized norepinephrine inhibits outgrowth via $\beta_{1}$-adrenoceptors. Immunohistochemistry revealed $\beta_{1}$-adrenoceptor protein on sympathetic axon terminations. In rats with coronary artery ligation, propranolol reversed heart failure-induced ventricular myocardial sympathetic axon depletion, but did not affect infarct-associated sympathetic hyperinnervation. We conclude that sympathetic neurons possess $\beta_{1}$-autoreceptors that negatively regulate axon outgrowth. Chronic $\beta$-adrenoceptor blockade disrupts this feedback system, leading to ventricular sympathetic axon proliferation and increased neuroeffector gain, which are likely to contribute to $\beta$-blocker withdrawal syndrome.
\end{abstract}

\section{Introduction}

$\beta$-Adrenergic receptor (AR) antagonists are commonly used clinically to treat conditions associated with excessive effects of norepinephrine (NE) and epinephrine, including hypertension, congestive heart failure, arrhythmias, and risk of sudden cardiac death (Yusuf et al., 1985; Viskin et al., 1995; Rodriguez-Ospina and Montano-Soto, 2008; Germino, 2009). In the heart, $\beta$-blockers inhibit catecholamine interactions with $\beta$-adrenergic G-protein-coupled receptors, thus preventing $\mathrm{G}_{\mathrm{s}}$-protein activation, formation of cAMP, and activation of protein kinase A (Lefkowitz, 2004). As a result, calcium influx and contractile force are decreased (Wang et al., 2004), thus reducing cardiac

\footnotetext{
Received March 30, 2010; revised June 30, 2010; accepted July 27, 2010.

This work was supported by National Institutes of Health Grant HL079652 with core support from Grant HD002528. We thank Timothy Donohue, Dora Krizsan-Agbas, Zhaohui Liao, Elza Kharatyan, Michelle Winter, and Kenneth McCarson for their assistance.

The authors declare no competing financial interests.

Correspondence should be addressed to Dr. Peter G. Smith, Hemenway Life Sciences Innovation Center, Mail Stop 3051, 3901 Rainbow Boulevard, University of Kansas Medical Center, Kansas City, KS 66160. E-mail address: psmith@kumc.edu.

W. Hasan's present address: Department of Physiology and Pharmacology, Oregon Health and Science University, Portland, OR 97239.

DOI:10.1523/JNEUROSCI.1667-10.2010

Copyright $\odot 2010$ the authors $\quad$ 0270-6474/10/3012446-09\$15.00/0
}

inotropy, chronotropy, and dromotropy, and decreasing arterial blood pressure and myocardial oxygen demand.

Although $\beta$-blockers are generally considered safe and effective, cessation of treatment can be accompanied by chest pain, hypertension, arrhythmias, myocardial infarction, and increased risk of mortality (Miller et al., 1975; Harrison and Alderman, 1976; Nattel et al., 1979; Hoeks et al., 2007). Adverse effects are attributed to exaggerated sympathoadrenal responsiveness, generally ascribed to increased $\beta$-receptor density and sensitivity resulting from long-term receptor blockade (Aarons et al., 1980; Heilbrunn et al., 1989). Although altered $\beta$-AR responsiveness certainly contributes to increased sympathoadrenal tone, it does not explain all facets of the withdrawal syndrome (Dollery and Maling, 1979). For example, after $\beta$-blocker discontinuation, serum NE is paradoxically elevated (Nattel et al., 1979; Vincent et al., 2009), suggesting increased sympathetic transmitter release.

We hypothesized that, similar to some central neurons (Haydon et al., 1984; Whitaker-Azmitia and Azmitia, 1986), peripheral sympathetic neurons possess prejunctional autoreceptors that inhibit axonal outgrowth. If so, then chronic AR blockade could promote axonal growth, thus leading to increased sympathetic innervation density. Since sympathetic hyperinnervation is believed to underlie enhanced end-organ responsiveness (Kondo et al., 1996), this could contribute to exaggerated sympathetic activity after $\beta$-blocker withdrawal. 

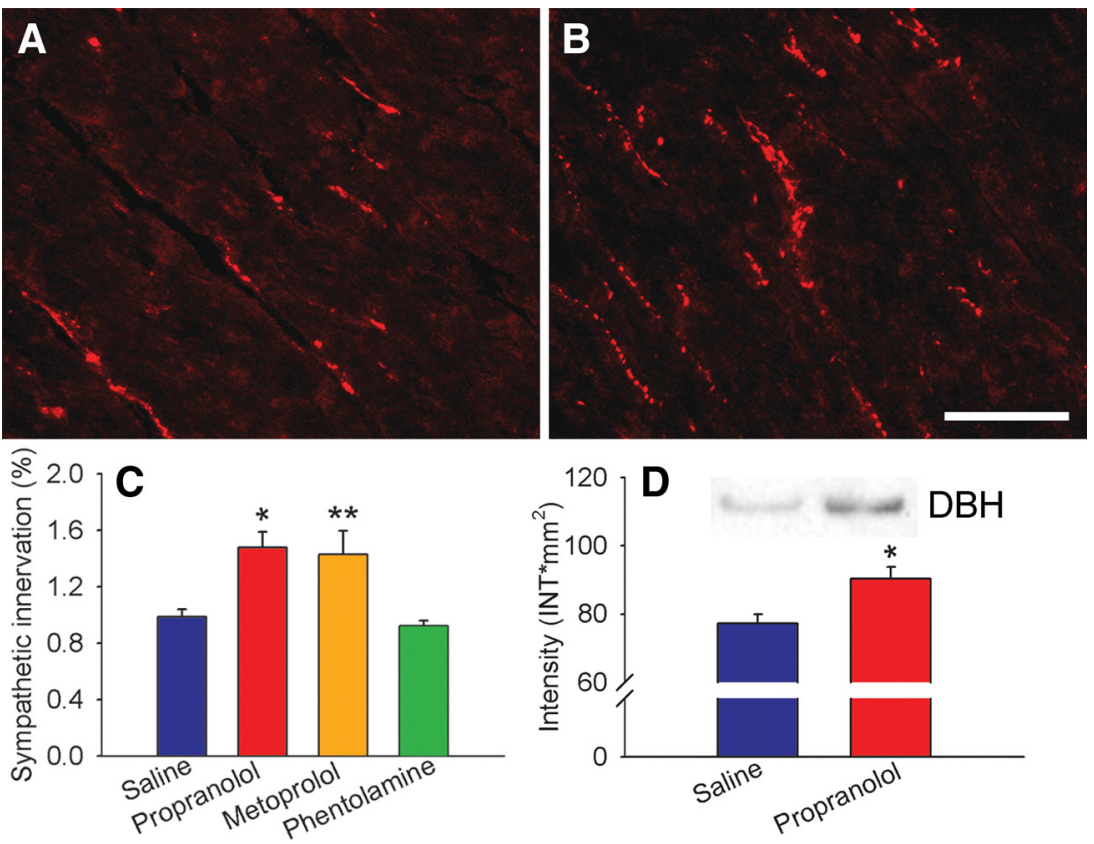

Figure 1. Adrenergic receptor blockade increases ventricular sympathetic innervation. $A$, Section of ventricular myocardium from a saline-infused rat showing dopamine $\beta$-hydroxylase-immunoreactive sympathetic axons. $\boldsymbol{B}$, Innervation density appears to be increased after a $7 \mathrm{~d}$ infusion of propranolol. C, Quantitative analyses of dopamine $\beta$-hydroxylase-immunoreactive innervation expressed as percentage of myocardial field area occupied by stained axons. Relative to saline-infused rats $(n=12)$, myocardial innervation density was increased by infusions of propranolol $(n=8)$ and metoprolol $(n=6)$ but not by phentolamine $(n=4)$. $\boldsymbol{D}$, Ventricular tissue from adjacent sections assessed by Western blot shows that propranolol also increases DBH protein levels. Product was analyzed densitometrically and normalized to total protein. Scale bar, $100 \mu \mathrm{m}$. Results are presented as the mean \pm SEM. ${ }^{*} p<0.05$ or ${ }^{* *} p<0.01$ versus saline.

\section{Materials and Methods}

Adrenoceptor blockade. All experiments conformed to the Guide for the Care and Use of Laboratory Animals (National Institutes of Health publication No. 85-23, 1996) and were approved by the University of Kansas Medical Center Animal Care and Use Committee. Unless otherwise indicated, drugs and reagents were purchased from Sigma. Female Sprague Dawley rats (Harlan Laboratories) aged $60 \mathrm{~d}$ were anesthetized by a mixture of ketamine $\mathrm{HCl}$, atropine sulfate, and xylazine (Wernli et al., 2009), and minipumps (Durect Corporation) were implanted. Rats received weeklong infusions of saline, propranolol (13.2 mg/kg/d) (Conlon et al., 1991), phentolamine ( $1 \mathrm{mg} / \mathrm{kg} / \mathrm{d}$ ) (Steinle and Smith, 2002), or metoprolol (36 mg/kg/d) (Ablad et al., 1975; DiBona and Sawin, 1999). Effectiveness of blockade was confirmed $7 \mathrm{~d}$ after minipump implantation in rats anesthetized with urethane $(1.5 \mathrm{~g} / \mathrm{kg}$ supplemented as needed). Phentolamine prevented normal $\alpha$-AR-mediated increases in pupil diameter after application of $1 \%$ NE to the eye. Propranolol and metoprolol blocked tachycardic responses to intravenous isoproterenol by 79 and $45 \%$, respectively, assessed electrocardiographically. The selectivity of metopropolol for $\beta_{1}$-AR (Ablad et al., 1975; DiBona and Sawin, 1999 ) was confirmed by showing that isoproterenol-induced $\beta_{2}$-AR-mediated increases in gracilis muscle blood flow measured by laser Doppler flowmetry (OxyFlow, Oxford Optronix Ltd) were unimpaired.

Cardiac sympathetic neuroeffector function after $\beta$-blocker discontinuation. Minipumps containing propranolol or saline were removed with ketamine-xylazine-atropine anesthesia, and, $48 \mathrm{~h}$ later, a calibrated catheter (SPR 838, Millar Instruments) for measuring pressure-volume relationships was introduced into the left ventricle (Pacher et al., 2008) under urethane anesthesia. After recording resting cardiac hemodynamics, the autonomic ganglionic blocker chlorisondamine $(2.5 \mathrm{mg} / \mathrm{kg}$; Ciba Pharmaceuticals) was administered intravenously. Tyramine was administered in graded doses until maximum changes were achieved $(70 \mu \mathrm{g} / \mathrm{kg})$, and after return to baseline values this was repeated using isoproterenol $(0.35 \mu \mathrm{g} / \mathrm{kg})$. Neuroeffector function and receptor sensitivity was calculated using
LabChart software (AD Instruments) and PVAN Software (Millar Instruments) (Pacher et al., 2008).

Cardiovascular reactivity to stress after discontinuation of $\beta$-AR blockade was assessed in a second group of awake unanesthetized rats. Two days after pump removal, rats were placed in restrainers set on a warming platform and occluding/pressure sensor cuffs positioned at the base of the tail. After an acclimation period of $40 \mathrm{~min}$, rats received an air puff directed toward the whiskers. After a recovery period during which blood pressure returned to baseline, rats were subjected to a loud noise $(\sim 110$ $\mathrm{db})$ generated using an air horn. Systolic and diastolic pressures were recorded during control periods and after startle using a CODA rat blood pressure system (Kent Scientific), and data are expressed as mean arterial pressures.

Ventricular sympathetic innervation density. After week-long minipump infusions, hearts were frozen, cryosectioned at $10 \mu \mathrm{m}$, and sympathetic innervation was immunostained with an antibody to dopamine- $\beta$ hydroxylase (DBH; Immunostar) after methanol fixation (Wernli et al., 2009). In deidentified sections, images of six fields evenly distributed within the left lateral posterior area of the ventricle were captured. Nerve density was measured using a stereological grid point-counting approach, as described previously (Wernli et al., 2009) and expressed as the percentage of field area occupied by $\mathrm{DBH}$-immunoreactive (ir) axons.

Ventricular DBH content was measured in Western blots obtained using sections adjacent to those used for morphometric analysis. The left lateral posterior ventricular tissue from eight sections per heart was lysed in cell extraction buffer (Invitrogen) with protease and phosphatase inhibitors and phenylmethanesulfonylfluoride. Proteins transferred from PAGE gels were probed with DBH antibody (Immunostar) followed by incubation with donkey anti-rabbit antibody-conjugated to HRP (Jackson Laboratory). Band intensity was normalized to that of total protein visualized with india ink, and mean intensity was calculated for each rat.

NGF in cardiomyocyte cultures. Hearts harvested from rat pups were disassociated (Worthington Biochemical) and cardiomyocytes plated in DMEM/F12 (Invitrogen) with fetal bovine serum and cytosine arabinoside. After $3 \mathrm{~d}$, cultures were incubated with medium alone containing phenylephrine $(0.1-10 \mu \mathrm{M})$ or isoproterenol $(0.1-10 \mu \mathrm{M})$. Media was collected after $24 \mathrm{~h}$, and proteins were precipitated and resolved using SDS-PAGE. Transferred proteins were probed in triplicate with an antibody to NGF (M-20, Santa Cruz Biotechnology) followed by incubation in goat anti-rabbit AP-conjugated (Jackson Laboratory) and detected (Wernli et al., 2009). NGF antibody specificity was confirmed by stripping a positive membrane (Thermo Scientific) and reprobing it using the antibody after it had been incubated overnight with a 10 -fold excess by weight of NGF-blocking peptide (Santa Cruz Biotechnology). Some membranes were probed using an antibody directed against an epitope in the pro region of pro-NGF (Millipore Bioscience Research Reagents). Sensitivity of the NGF antibody was demonstrated by loading $0.01-1 \mu \mathrm{g}$ of human recombinant $\beta$-NGF (Sigma) onto membranes subsequently probed with the NGF antibody. Cultured cardiomyocytes were fixed in $4 \%$ paraformaldehyde and stained for actin (Alexa Fluor594-Phalloidin), with the NGF antibody or with a furin antibody (Santa Cruz Biotechnology).

Sympathetic neuronal cultures. Superior cervical ganglion (SCG) neurons were obtained from newborn rats, dissociated with collagenase IA and trypsin, suspended in neurobasal medium (Invitrogen) with glutamine, B27 (Invitrogen), primocin (InvivoGen), fluorodeoxyuridine, 
and uridine, and $10 \mathrm{ng} / \mathrm{ml}$ NGF (Alomone Labs). Neurons were plated on glass coverslips (Bellco) coated with poly-D-lysine (MP Biomedicals) and laminin (Invitrogen) in control medium or medium containing propranolol $\left(10^{-10}\right.$ to $\left.10^{-8} \mathrm{M}\right)$ or metoprolol $\left(10^{-8}\right.$ to $\left.10^{-6} \mathrm{M}\right)$. Other cultures were conducted with $10^{-10}-10^{-6} \mathrm{M}$ dobutamine, with or without $5 \mu \mathrm{M} \alpha$-methyl-p-tyrosine (AMPT, Research Biochemicals International) or with AMPT alone.

After $48 \mathrm{~h}$, cultures were fixed in $4 \%$ parafomaldehyde and immunostained using a peripherin antibody (Millipore Bioscience Research Reagents). Neurite outgrowth was measured blindly in six captured images distributed equally within each well using a stereological grid with intersections at $25 \mu \mathrm{m}$ intervals superimposed over each image. Intersections overlying stained neurites were divided by total intersections within the field (fraction of field occupied by neurites) and multiplied by total field area (neurite area per field area). This was divided by the total number of neuronal somata within the field (neurite area per neuron), and values were normalized to $1 \mathrm{~mm}^{2}$ (Chakrabarty et al., 2008). Cultures were also double stained for peripherin and $\beta_{1}$-AR (Santa Cruz Biotechnology).

Reverse transcriptase-PCR for $\beta_{1}$-receptor mRNA. $\beta_{1}$-AR gene expression was assessed in SCG cultures by reverse transcriptase (RT)-PCR. Fresh heart tissue or SCG neurons were homogenized, and total RNA was reverse transcribed (Wernli et al., 2009). Amplification of cDNA was conducted using primers for $\beta_{1}$-AR (5'-CAACGGCGGGACGACCACTG-3' sense; and 5'-ACACCTTGGACTCGGAGGAGAGC-3' antisense) and glyceraldehyde-3-phosphate dehydrogenase (GAPDH) (5'-CTCTACCCACGGCAAGTTC- ${ }^{\prime}$ ' sense; and 5' -CTCAGCACCAGCATCACC- $3^{\prime}$ antisense), and analyzed by electrophoresis.

Myocardial infarction. To assess the effects of $\beta$-AR blockers in rats with myocardial infarction, coronary artery ligation (CAL) was performed by ligating the left descending coronary artery (Wernli et al., 2009), or the artery was exposed but left unoccluded. Concurrently, rats received pump infusions of AR antagonists or saline for $7 \mathrm{~d}$. In CAL hearts, images were obtained of six fields distributed evenly along the left lateral posterior infarct border region where sympathetic hyperinnervation occurs. In addition, images of six fields evenly distributed within the nonischemic posterior area of the left ventricle were also obtained. Procedures and analyses were as described above.

Statistics. Data were analyzed using one-way ANOVA for multiple comparisons followed by Newman-Keuls test. Data are expressed as the mean \pm SEM. Statistical significance was accepted at $p<0.05$.

\section{Results}

\section{AR blockade increases ventricular sympathetic innervation in vivo}

Rats received $7 \mathrm{~d}$ infusions of saline, the nonselective $\beta$-blocker propranolol, the selective $\beta_{1}$-blocker metoprolol, or the nonselective $\alpha$-blocker phentolamine. In rats receiving saline, quantitative analysis of $\mathrm{DBH}$-ir sympathetic axons showed that ventricular innervation occurred at a density similar to that reported previously (Wernli et al., 2009) (Fig. 1A). DBH-ir fibers appeared more abundant in rats receiving propranolol (Fig. $1 B$ ) and quantitative analysis revealed a $48 \%$ increase in ventricular sympathetic axon density $(p<0.05)$ (Fig. $1 C$ ). Analysis of adjacent tissue by Western blot confirmed that $\mathrm{DBH}$ protein content was also significantly increased (Fig. $1 D$ ). Because propranolol blocks both $\beta_{1}$ - and $\beta_{2}$-ARs, we examined whether selective blockade of $\beta_{1}$-AR alone increases innervation density. Metoprolol was administered using a comparable regimen, and quantitative analysis showed a $44 \%$ increase in sympathetic innervation relative to controls $(p<0.01)$ (Fig. $1 C$ ). To assess whether other $\mathrm{AR}$ antagonists with depressor effects also affect ventricular innervation, we administered the $\alpha$-blocker phentolamine. DBH-ir fiber density after phentolamine treatment was similar to that of controls (Fig. $1 C$ ), showing that $\alpha$-blockade and the associated decrease in blood pressure does not modify cardiac sympathetic innervation.
Table 1. Cardiac function in response to isoproterenol and tyramine

\begin{tabular}{|c|c|c|}
\hline & Saline $(n=8)$ & Propranolol $(n=\varepsilon$ \\
\hline \multicolumn{3}{|l|}{ Resting } \\
\hline HR, bpm & $400 \pm 14$ & $411 \pm 13$ \\
\hline $\mathrm{ESP}, \mathrm{mmHg}$ & $124 \pm 12$ & $131 \pm 10$ \\
\hline $\mathrm{EDP}, \mathrm{mmHg}$ & $7.7 \pm 2.8$ & $4.0 \pm 0.5$ \\
\hline Peak dP/dt ${ }_{\max }, \mathrm{mmHg} / \mathrm{s}$ & $11,808 \pm 1,275$ & $14,497 \pm 825$ \\
\hline Peak dP/dt $t_{\min }, \mathrm{mmHg} / \mathrm{s}$ & $8,229 \pm 788$ & $9,081 \pm 709$ \\
\hline \multicolumn{3}{|l|}{ Chlorisondamine } \\
\hline $\mathrm{HR}, \mathrm{bpm}$ & $342 \pm 10$ & $350 \pm 8$ \\
\hline $\mathrm{ESP}, \mathrm{mmHg}$ & $60 \pm 3$ & $68 \pm 4$ \\
\hline $\mathrm{EDP}, \mathrm{mmHg}$ & $6.9 \pm 0.9$ & $4.8 \pm 0.4$ \\
\hline Peak dP/dt ${ }_{\max }, \mathrm{mmHg} / \mathrm{s}$ & $2,169 \pm 145$ & $2,705 \pm 196^{*}$ \\
\hline Peak dP/dt $\mathrm{min}_{1}, \mathrm{mmHg} / \mathrm{s}$ & $2,131 \pm 263$ & $3,335 \pm 380^{*}$ \\
\hline \multicolumn{3}{|l|}{ Isoproterenol } \\
\hline $\mathrm{HR}, \mathrm{bpm}$ & $461 \pm 12$ & $479 \pm 11$ \\
\hline $\mathrm{ESP}, \mathrm{mmHg}$ & $88 \pm 5$ & $93 \pm 5$ \\
\hline $\mathrm{EDP}, \mathrm{mmHg}$ & $3.9 \pm 0.7$ & $2.5 \pm 0.4$ \\
\hline Peak $\mathrm{dP} / \mathrm{dt}_{\max }, \mathrm{mmHg} / \mathrm{s}$ & $8,476 \pm 739$ & $9,552 \pm 297$ \\
\hline Peak dP/dt ${ }_{\min }, \mathrm{mmHg} / \mathrm{s}$ & $4,894 \pm 476$ & $5,731 \pm 779$ \\
\hline \multicolumn{3}{|l|}{ Tyramine } \\
\hline $\mathrm{HR}, \mathrm{bpm}$ & $434 \pm 17$ & $458 \pm 16$ \\
\hline $\mathrm{ESP}, \mathrm{mmHg}$ & $83 \pm 3$ & $103 \pm 8^{*}$ \\
\hline $\mathrm{EDP}, \mathrm{mmHg}$ & $4.9 \pm 0.7$ & $2.9 \pm 0.5^{*}$ \\
\hline Peak $\mathrm{dP} / \mathrm{dt}_{\max }, \mathrm{mmHg} / \mathrm{s}$ & $8,081 \pm 688$ & $10,922 \pm 581^{* *}$ \\
\hline Peak dP/dt $\mathrm{dmin}_{1}, \mathrm{mmHg} / \mathrm{s}$ & $5,427 \pm 622$ & $6,881 \pm 696$ \\
\hline
\end{tabular}

Responses obtained $48 \mathrm{~h}$ after discontinuation of a $7 \mathrm{~d}$ infusion of saline or propranolol. Values were obtained in the resting state under urethane anesthesia, after ganglionic blockade with chlorisondamine, and after a maximally effective dose of the direct $\beta$-agonist isoproterenol, or displacement of sympathetic norepinephrine stores by a maximal dose of tyramine. Results are presented as the mean \pm SEM. HR, Heart rate; bpm, beats per minute; ESP, end systolic pressure; EDP, end diastolic pressure. ${ }^{*} p<0.05$ versus saline infusion; ${ }^{* *} p<0.01$.

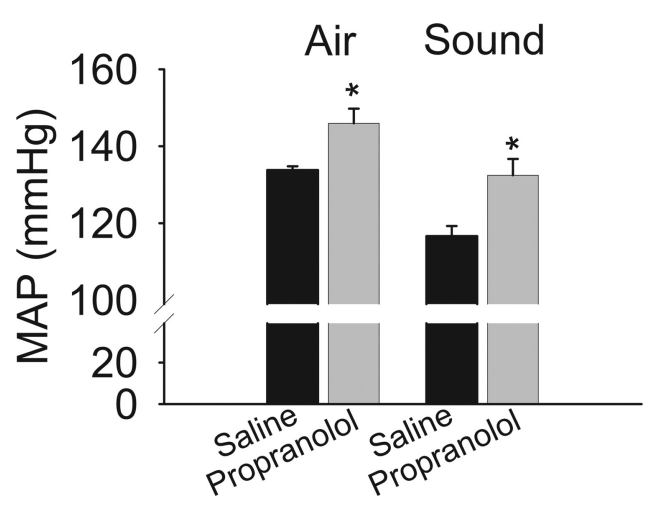

Figure 2. Cardiovascular responses to stressors are increased after $\beta$-blockade discontinuation. Arterial pressure was measured in awake, restrained rats $2 \mathrm{~d}$ after discontinuation of propranolol $(n=5)$ or saline $(n=4)$ infusion. Mildly restrained animals were subjected to stress induced by a puff of air to the facial region (Air) or sound of $\sim 110 \mathrm{db}$ generated by an air horn (Sound). Peak values are presented as mean arterial pressure (MAP). ${ }^{*} p<0.05$ versus saline.

\section{Ventricular sympathetic neuroeffector function and cardiovascular reflexes are enhanced after $\boldsymbol{\beta}$-blocker discontinuation}

To determine whether sympathetic hyperinnervation is associated with altered ventricular sympathetic neuroeffector properties, we assessed cardiac function $48 \mathrm{~h}$ after discontinuation of saline or propranolol infusions. Resting heart rate, ventricular pressures (end systolic and end diastolic pressures), and rates of ventricular contraction $\left(\mathrm{dP} / \mathrm{dt}_{\max }\right)$ and relaxation $\left(\mathrm{dP} / \mathrm{dt}_{\min }\right)$ were similar between groups (Table 1). Elimination of autonomic tone by the ganglionic blocker chlorisondamine reduced all values, and function was comparable between groups for all parameters except for modest increases in $\mathrm{dP} / \mathrm{dt}_{\text {max }}$ and $\mathrm{dP} / \mathrm{dt}_{\text {min }}$ in rats receiving propranolol. 


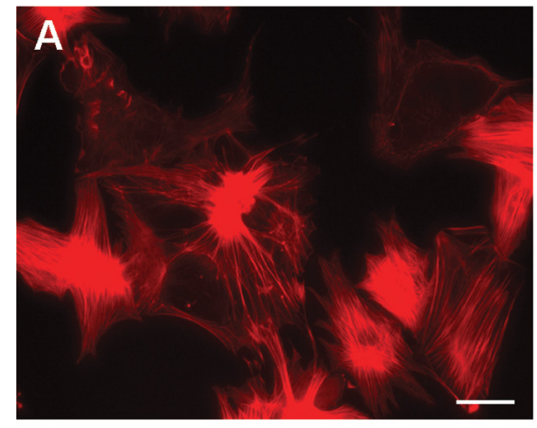

D

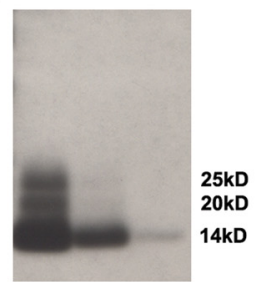

$1 \quad 0.1 \quad 0.01$ rh-NGF $(\mu \mathrm{g})$

$\mathbf{E}$
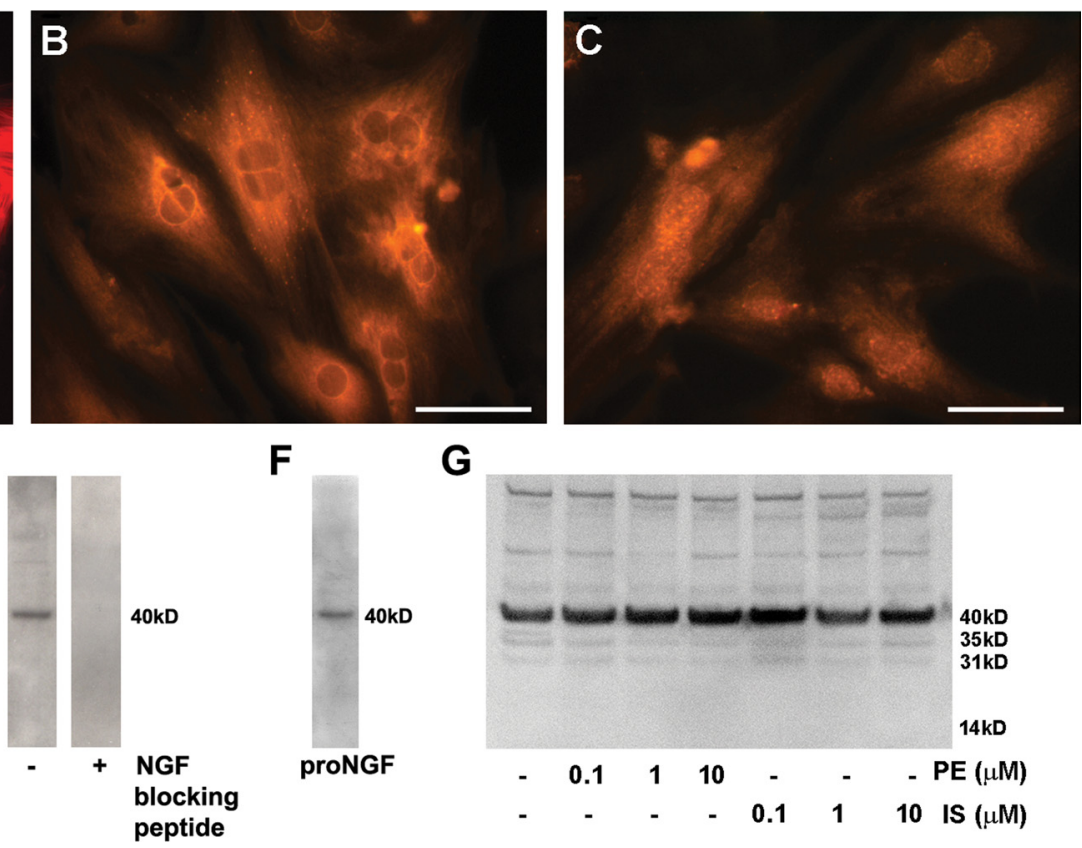

F

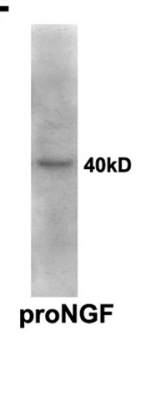

G

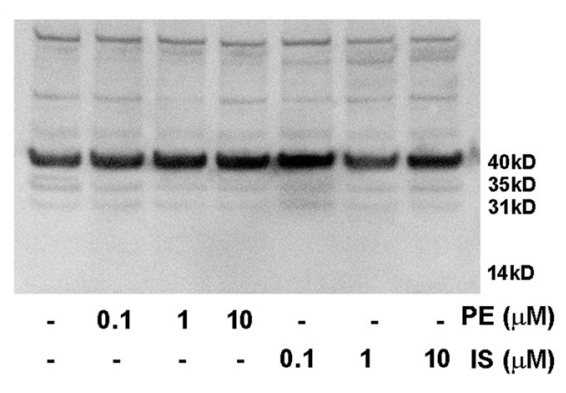

Figure 3. Adrenergic receptors do not modulate cardiomyocyte NGF secretion. Dissociated cardiomyocytes were cultured for $3 \mathrm{~d}$ before treatment with phenylephrine or isoproterenol. $A$, Cardiomyocytes in culture show typical actin cytoskeleton after staining with phalloidin. $\boldsymbol{B}, \boldsymbol{C}$, Cardiomyocytes express NGF protein $(\boldsymbol{B})$ and the pro-neurotrophin convertase furin (C). Scale bars, 50 $\mu \mathrm{m} . \boldsymbol{D}$, Staining of Western blots loaded with different amounts of recombinant human $\beta$-NGF showed that antibody sensitivity is at least $10 \mathrm{ng} /$ lane. $\boldsymbol{E}$, After culture for $48 \mathrm{~h}$, Western blot analysis of the culture medium revealed immunoreactive NGF, mainly as pro-NGF with a molecular mass of $\sim 40 \mathrm{kDa}$ (left) and preincubation of the antibody with an NGF-blocking peptide resulted in absence NGF detection (right). $\boldsymbol{F}$, Probing with an antibody recognizing a non-NGF epitope in the pro region of the protein confirmed that the 40 kDa band is pro-NGF. $\mathbf{G}$, Treatment of the cardiomyocyte cultures with 0.1-10 $\mu$ m concentrations of the $\alpha$-agonist phenylephrine (PE) or the $\beta$-agonist isoproterenol (IS) did not alter NGF content within the medium.

We administered the $\beta$-AR agonist isoproterenol to assess whether receptor sensitivity was altered at $48 \mathrm{~h}$ after propranolol discontinuation, and whether cardiac function in response to $\operatorname{direct} \beta$-AR activation was affected. To assess receptor sensitivity, incremental doses of isoproterenol were administered to achieve maximum values for heart rate and $\mathrm{dP} / \mathrm{dt}_{\max } . \mathrm{ED}_{50}$ values were comparable in saline- and propranolol-infused rats $(0.07 \pm 0.02$ vs $0.07 \pm 0.02 \mathrm{mg} / \mathrm{kg}$ for heart rate, $0.09 \pm 0.02$ vs $0.10 \pm 0.02$ $\mu \mathrm{g} / \mathrm{kg}$, respectively, for $\mathrm{dP} / \mathrm{dt}_{\max }$ in saline- or propranololinfused rats), confirming prior reports that $\beta$-AR sensitivity in humans and rats is normal at this time after discontinuation (Nattel et al., 1979; Hedberg et al., 1980). All values for heart rate and left ventricular function in response to maximally effective doses of isoproterenol were comparable in saline- and propranolol-infused rats (Table 1).

To determine whether indices of sympathetic neuroeffector transmission are enhanced in ventricles with increased sympathetic axon density, we administered maximally effective doses of tyramine, which acts by displacing sympathetic NE stores. In saline- and propranolol-infused rats, maximum heart rate was comparable, but rats after $\beta$-blockade showed significantly greater ventricular end-systolic pressures (despite decreased enddiastolic pressure) and significantly increased rate of contraction (Table 1).

To determine whether cardiovascular reflexes that are normally mediated by the sympathetic nervous system are also enhanced after $\beta$-AR blocker discontinuation in unanesthetized rats, we assessed the effects of two common stressors on blood pressure. A puff of air delivered to the facial region of restrained rats resulted in greater increase in blood pressure after propranolol than after saline discontinuation. Similarly, loud noise also increased blood pressure to a greater extent after propranolol than saline infusion (Fig. 2).

\section{Adrenoceptors and cardiomyocyte NGF synthesis}

$\beta$-ARs modulate NGF synthesis in some cell types (Colangelo et al., 1998), and altered neurotrophin synthesis is a possible mechanism for the observed increase in ventricular sympathetic axon density. To determine whether $\beta$-ARs influence cardiac NGF synthesis, we cultured ventricular cardiomyocytes in the presence or absence of AR agonists and measured NGF protein produced and secreted in vitro. Cardiomyocytes in culture showed spontaneous contractions and mature cytoskeletal features (Fig. 3A). These cells were immunoreactive for NGF protein (Fig. $3 B$ ), and the endopeptidase furin (Fig. $3 \mathrm{C}$ ), which converts pro-NGF to mature NGF, the pro-neuritogenic form of this neurotrophin. To assess NGF secretion by these cells, we probed Western blots using an antibody to NGF. In characterization studies, this antibody detected $\leq 10 \mathrm{ng}$ of the $14 \mathrm{kDa}$ mature recombinant human NGF and higher molecular weight forms of NGF at higher concentrations (Fig. 3D). Medium from cultured myocytes showed a dominant band at $\sim 40 \mathrm{kDa}$, which was eliminated preabsorbing the NGF antibody with an excess of blocking peptide (Fig. 3E). Probing membranes with an antibody directed to the non-NGF portion of pro-NGF confirmed that this band is pro-NGF (Fig. $3 F$ ). To assess whether NGF-related protein secretion is regulated by ARs, cardiomyocytes were incubated with $10^{-7}-10^{-5} \mathrm{M}$ of the $\alpha$-agonist phenylephrine or the $\beta$-agonist isoproterenol. Isoproterenol treatment did not appear to alter the amount or pattern of secreted protein. Similarly, phenylephrine did not have marked effects on NGF-related proteins, although lower molecular weight forms may have been decreased at higher concentrations (Fig. 3G).

\section{AR blockade increases sympathetic neuritogenesis in vitro}

To determine whether $\beta$-AR blockers act directly on sympathetic neurons to increase axon outgrowth, we used an in vitro assay 
system consisting of neonatal SCG sympathetic neurons cultured in defined media. After $48 \mathrm{~h}$, SCG neurons in control cultures had elaborated many neurites (Fig. 4A). Neurons cultured with $10-{ }^{10} \mathrm{M}$ propranolol appeared to have greater neurite outgrowth (Fig. 4B), and quantitative analysis confirmed a significant increase in neurite area per neuron (Fig. 4C). However, cultures containing propranolol at the greater concentration of $10^{-8} \mathrm{M}$ yielded outgrowth comparable to controls (Fig. 4C).

To assess whether the propranololinduced increase in outgrowth is attributable to blockade of $\beta_{1}$-AR, we cultured SCG neurons in the presence of metoprolol. Cultures containing $10^{-8} \mathrm{M}$ metoprolol showed substantial neurite outgrowth (Fig. 4D) similar to that of propranolol. Quantitative analysis confirmed that this concentration of metoprolol increased neurite outgrowth by 29\% (Fig. 4 E). Cultures containing a higher concentration of $10^{-6} \mathrm{M}$ metoprolol again showed outgrowth comparable to controls (Fig. $4 E$ ).

Sympathetic axons contain $\beta_{2}$-ARs that are known to enhance NE release (Deegan et al., 1995). We assessed whether these receptors play a role in modulating sympathetic neurite outgrowth by incubating SCG neurons with the $\beta_{2}$-AR antagonist ICI 118551. Sympathetic outgrowth was comparable to control cultures at all concentrations tested (Fig. $4 F$ ).

To confirm that outgrowth mediated by $\beta_{1}$ blockade is not caused by increased neuronal survival, numbers of somas per square millimeter were compared. We observed no differences in neuron numbers with different concentrations of propranolol (Fig. 4G) or metoprolol (Fig. 4H). Similarly, ICI 118551 did not alter neuron numbers (data not shown).

\section{SCG neurons express $\boldsymbol{\beta}_{1}$-AR mRNA and protein in culture}

To confirm that sympathetic neurons express $\beta_{1}$-AR mRNA, we performed RTPCR analysis of SCG neurons after $48 \mathrm{~h}$ in culture. The sensitivity of our primers was confirmed using ventricular myocardium as a control, which showed a strong band at the predicted product size. RT-PCR of SCG neurons also yielded PCR product of the correct size, albeit of less intensity than that of cardiac muscle (Fig. $5 A$ ). The presence of the $\beta_{1}$-AR protein in somata and neurites was evaluated in cultures stained for $\beta_{1}$-AR protein (Fig. $5 B)$. Cultures were costained with the neuronal marker peripherin (Fig. $5 C$ ), and merged images showed that $\beta_{1}$-AR protein is distributed widely throughout soma and neurites (Fig. 5D). $\beta_{1}$-AR immunostaining of cells not known to express this protein was negligible (Fig. 5B, inset, glia).
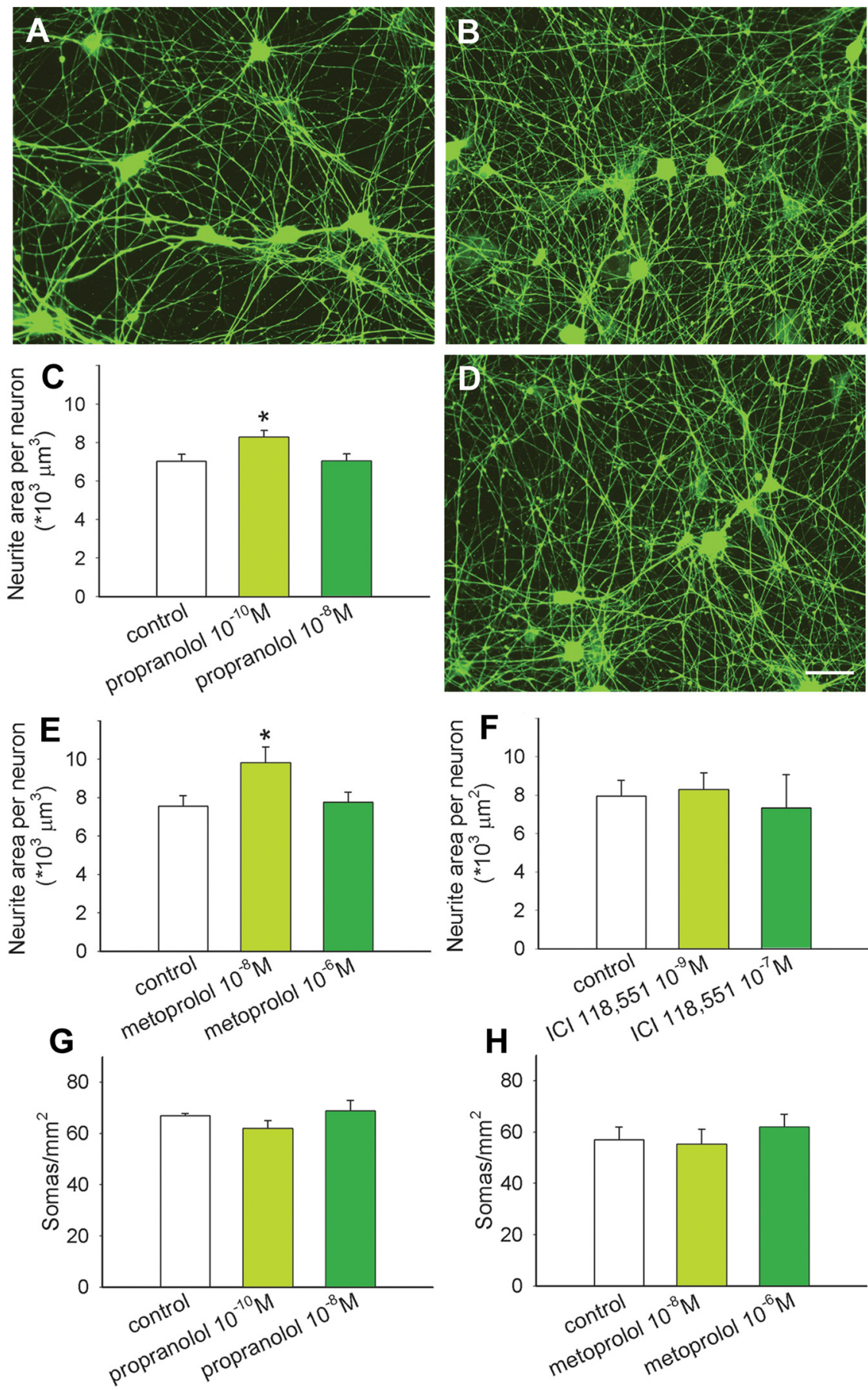

Figure 4. $\quad \beta_{1}$ adrenoceptors promote sympathetic neurite outgrowth. $A$, Superior cervical sympathetic ganglion neurons cultured without treatment extend many neurites. $B, C$, Addition of propranolol at a concentration of $10^{-10} \mathrm{M}$ appeared to increase neurite outgrowth $(\boldsymbol{B})$, and this was confirmed by quantitative analysis of peripherin-immunoreactive neurite area $(\boldsymbol{C})(n=12$ per condition). $\boldsymbol{D}, \boldsymbol{E}$, Cultures treated in the presence of $10^{-8} \mathrm{M}$ metoprolol $(\boldsymbol{D})$ showed increased neurite outgrowth similar to propranolol, and this was confirmed by quantitative analysis $(\boldsymbol{E})(n=12) . \boldsymbol{F}$, Treatment with the $\beta_{2}$-antagonist ICI 118551 had no effect on neurite outgrowth $(n=3) . \boldsymbol{G}, \boldsymbol{H}$, Counts of neuronal somas per unit area showed no differences between control cultures and those treated with propranolol $(\boldsymbol{G})$ or metoprolol $(\boldsymbol{H})$. Scale bar: (in $\boldsymbol{D}) \boldsymbol{A}, \boldsymbol{B}, \boldsymbol{D}, 50 \mu \mathrm{m}$ for all micrographs. Results are presented as the mean \pm SEM. ${ }^{*} p<0.05$ compared with control.

\section{Norepinephrine synthesis inhibits neurite outgrowth}

We postulated that propranolol and metoprolol promote sympathetic axon sprouting by blocking $\beta_{1}$ receptors that negatively regulate outgrowth. Accordingly, we sought to determine whether activating sympathetic axonal $\beta_{1}$-ARs would suppress outgrowth in culture. We cultured SCG neurons alone (Fig. 6A) 


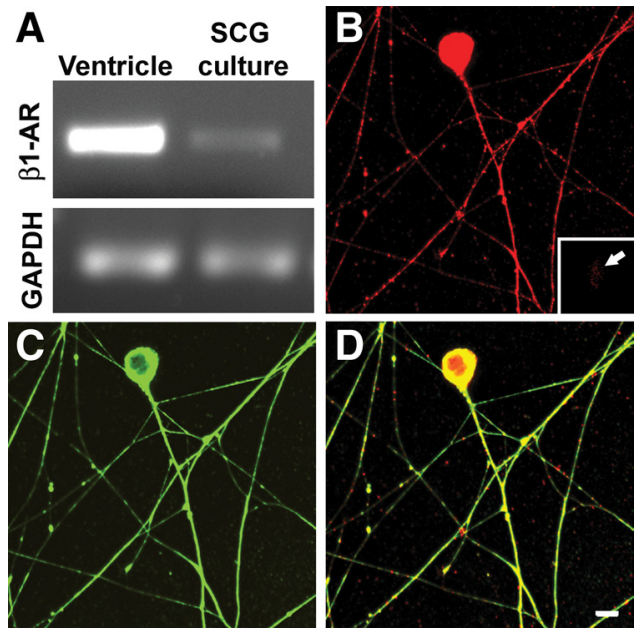

Figure 5. $\quad \beta_{1}$-Adrenoceptor protein and gene expression in cultured sympathetic neurons. $A$, mRNA extracted from purified SCG neuronal cultures contains sequences corresponding to the $\beta_{1}$-adrenoceptor gene, as revealed by RT-PCR. Ventricular myocardium was used as a positive control, and GAPDH was used to show the relative level of receptor expression. $\boldsymbol{B}, \boldsymbol{C}$, Immunostaining for $\beta_{1}$-adrenoceptor show that this protein is present in sympathetic neurons $(\boldsymbol{B})$, as revealed by peripherin staining $\left(\boldsymbol{C}\right.$ ). Inset in $\boldsymbol{B}$ shows a glial cell that is negative for $\beta_{1}-A R$ immunoreactivity. $D$, A merged image shows that $\beta_{1}$-adrenoceptor protein is present throughout the soma and processes including axon terminations. Scale bar, $10 \mu \mathrm{m}$.

or in the presence of the $\beta_{1}$-agonist dobutamine (Fig. $6 B$, a representative concentration of $10^{-8} \mathrm{M}$ is shown). Dobutamine did not seem to modulate neurite outgrowth (Fig. $6 B$ ) and quantitative analysis confirmed that dobutamine was ineffective in decreasing axonal outgrowth over a wide range of concentrations (Fig. 6C). However, because SCG neurons in culture express catecholamine biosynthetic proteins, it is likely that NE is synthesized and released in these cultures. If so, $\beta_{1}$-AR activation may be ongoing, thus masking effects of exogenously applied agonist.

To determine whether NE synthesized in culture tonically inhibits axonal outgrowth, we blocked NE synthesis with AMPT, a competitive inhibitor of tyrosine hydroxylase. Neurite outgrowth appeared to be greater in cultures containing AMPT (Fig. 6D), and quantitation confirmed a $35 \%$ increase relative to controls (Fig. $6 F$ ). To confirm that AMPT acted to increase neurite outgrowth by eliminating tonic $\beta_{1}$-AR activation, we now added dobutamine to these cultures. This $\beta_{1}$-agonist suppressed the AMPT-mediated increase in axon outgrowth to a level comparable to that of controls (Fig. $6 E, F$ ), confirming that locally synthesized NE inhibits sympathetic axon outgrowth in culture. Soma counts again confirmed that neurite changes are not the result of differential neuronal survival (data not shown).

\section{AR blockade increases ventricular sympathetic innervation after myocardial infarction}

An important clinical application of $\beta$-blockers is to reduce complications after myocardial infarction (Cao et al., 2000). To determine whether this is associated with changes in ventricular sympathetic axon density, we induced myocardial ischemia by performing CAL of the left anterior coronary artery (Hasan et al., 2006; Wernli et al., 2009) and infused saline or an AR antagonist for $7 \mathrm{~d}$; treatments did not affect infarct size (data not shown). In intact myocardium adjacent to the infarct, sympathetic innervation density was lower than that seen in uninjured subjects $(p<$ 0.01), consistent with prior reports (Kaye et al., 2000). However, propranolol (but not phentolamine) increased sympathetic axon density (41\%, $p<0.05$ ) (Fig. 7 ), restoring innervation toward that of control animals (Fig. 1, compare with normative values). Consistent with previous reports (Cao et al., 2000; Hasan et al. 2006; Wernli et al., 2009), the infarct border region showed marked sympathetic hyperinnervation in saline-infused rats, but this was unaffected by either propranolol or phentolamine treatment (Fig. 7).

\section{Discussion}

Our findings provide evidence that $\beta$-blockers increase sympathetic target organ innervation, which contributes to exaggerated sympathetic responses after $\beta$-blocker withdrawal. Chronic propranolol administration increased numbers of ventricular DBH-ir axons consistent with sprouting of existing sympathetic projections (Hasan et al., 2006; Wernli et al., 2009). Metoprolol was equally effective, indicating that newer selective $\beta$-antagonists share this property. Therefore, ventricular sympathetic hyperinnervation appears to be a feature common to at least some $\beta$-AR blockers that enjoy broad clinical use.

There is precedence for proposing that greater ventricular sympathetic axon density may contribute to enhanced target organ response. Increased sympathetic innervation is associated with smooth muscle hypertrophy and hyper-reactivity (Scott and Pang, 1983; Kondo et al., 1996), and our findings indicate that ventricular neuroeffector function is also exaggerated in hearts with $\beta$-blocker-induced hyperinnervation. Indices of contractile function in response to tyramine were significantly greater in rats after chronic $\beta$-AR blockade. Because the magnitude of the tyramine response is determined by the amount of NE that can be displaced from intrinsic sympathetic nerves, this increased response is consistent with greater NE stores in hearts with elevated innervation density. Moreover, $\beta$-AR sensitivity was normal at $48 \mathrm{~h}$ after withdrawal, as reported previously in rats and humans (Nattel et al., 1979; Hedberg et al., 1980), and responses to direct $\beta$-AR activation with isoproterenol were comparable, indicating that intrinsic ventricular properties during maximal $\beta$-AR activation are largely unchanged. It is noteworthy, however, that ventricular function after complete ganglionic blockade did show modest increases in the rate of contraction and relaxation, although no such differences were evident in the resting state or after isoproterenol. Whether this reflects ventricular remodeling, or possibly altered preload and afterload induced by chronic $\beta$-blockade, remains to be determined. Nonetheless, these changes are unlikely to contribute substantially to the enhanced cardiac function observed with tyramine in chronically blocked subjects. Accordingly, the increased tyramine response appears to represent a functional correlate to ventricular sympathetic hyperinnervation. Interestingly, no differences in heart rate were detected in the resting or stimulated state. Because the sympathetic innervation density of the sinoatrial node is substantially greater than that of the ventricle, it may be the case that $\beta$-blockade was less effective in increasing axon density in that region, as we find to be the case for peri-infarct hyperinnervation.

Although the tyramine response is a reliable indicator of potential sympathetic neuroeffector efficacy, it does not provide evidence that sympathetically mediated behavioral responses are also enhanced. To determine whether behavioral indices of sympathetic activation are altered, we assessed cardiovascular responsiveness to stressors in awake rats. Rats show startle responses when subjected to loud noise or a puff of air directed at the face. In both cases, at a time when tyramine response was enhanced but $\beta$-AR sensitivity was normal, mean arterial pressure was increased to greater levels in rats undergoing $\beta$-blocker withdrawal. This indicates that sympathetic nervous system 

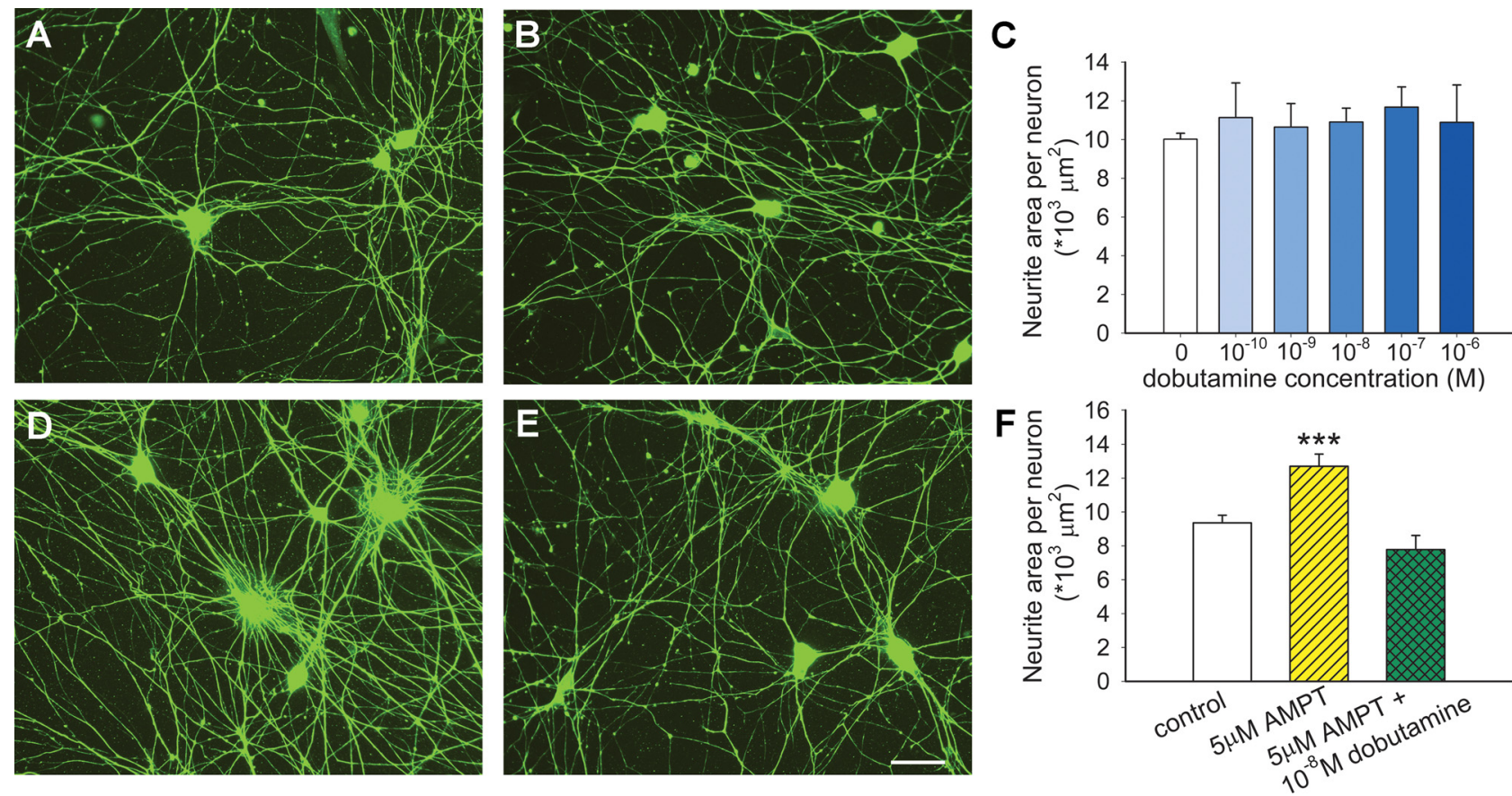

Figure 6. Sympathetic neurite outgrowth in culture is regulated by locally synthesized norepinephrine. $A-C$, Compared with control cultures $(A)$, dobutamine at a concentration of $10^{-8} \mathrm{M}$ failed to affect outgrowth $(\boldsymbol{B})$, and this was confirmed by quantitative analysis of neurite area over a wide range of concentrations $(\boldsymbol{C})(n=3$ per condition). $\boldsymbol{D}$, When norepinephrine synthesis was blocked by AMPT, neurite outgrowth appeared to be enhanced. $\boldsymbol{E}$, Addition of dobutamine to cultures in which norepinephrine synthesis was blocked led to diminished outgrowth. Scale bar, $50 \mu \mathrm{m}$. $\boldsymbol{F}$, Quantitative analysis confirmed that inhibition of NE synthesis by AMPT increases neurite area, and that $\beta_{1}$ activation by dobutamine is effective in reducing outgrowth only when NE synthesis is blocked. Results are presented as the mean \pm SEM. ${ }^{* * *} p<0.001$ versus control $(n=9)$ or versus AMPT + dobutamine $(n=6)$.

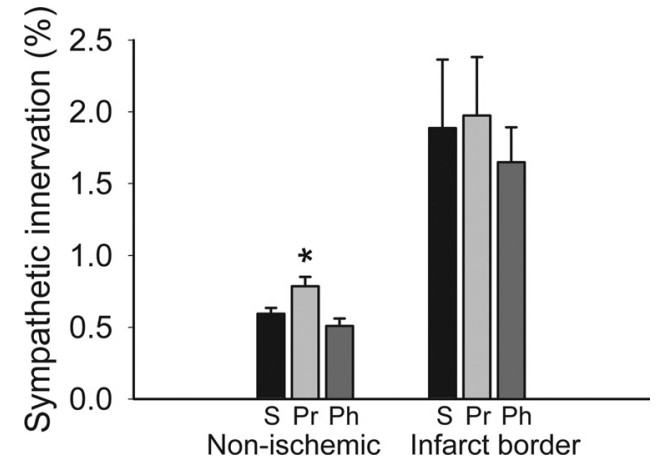

Figure 7. Adrenergic receptor blockade increases ventricular sympathetic innervation after coronary artery ligation. Quantitative analyses of dopamine $\beta$-hydroxylaseimmunoreactive innervation shows that regions of the ventricular myocardium remote to the infarct (Non-ischemic) have relatively low innervation density in saline-infused rats $(S ; n=4)$, and this was increased by propranolol $(\mathrm{Pr} ; n=4)$ but not by phentolamine ( $\mathrm{Ph}$; $n=4)$. Neither propranolol nor phentolamine altered the relatively high innervation density characteristic of the infarct border. Results are presented as the mean \pm SEM. ${ }^{*} p<0.05$ versus saline.

responsiveness is exaggerated in unanesthetized rats, and that rats, like humans, show increased cardiovascular lability after $\beta$-blocker withdrawal.

A central question concerns the mechanism by which $\beta$-blockers increase ventricular sympathetic axon density. In some cell types, $\beta$-ARs regulate synthesis of NGF, a powerful mediator of sympathetic sprouting (Dal Toso et al., 1987) that could initiate axon outgrowth. However, consistent with other reports (Kaye et al., 2000), our culture studies show that $\beta$-ARs do not appear to play a major role in regulating NGF synthesis and release by cardiac myocytes. Although treatment with an $\alpha$-agonist has been reported to suppress cardiac NGF synthesis
(Kaye et al., 2000), it did not significantly modify NGF expression in our hands, and our finding that ventricular sympathetic density was unchanged by phentolamine argues against substantial modulation of innervation by $\alpha$-ARs. In any event, an increase in NGF synthesis by $\beta$-AR blockers is unlikely to contribute to sympathetic hyperinnervation.

An alternative mechanism is a direct effect of $\beta$-antagonists on the sympathetic neuron itself. We demonstrate that $\beta_{1}$-AR mRNA and protein are present in sympathetic neuronal cell bodies and axons, which extends earlier pharmacological studies inferring the presence of $\beta_{1}$ receptors on cardiac sympathetic neurons (Butler et al., 1990; Watson-Wright et al., 1991). Hence, synthesis and distribution of $\beta_{1}$-ARs in sympathetic neurons are consistent with their potential role as an autoreceptor.

Our culture studies provide evidence that $\beta$-blockers induce sprouting by interfering with activation of the sympathetic $\beta_{1}$ autoreceptor. Thus, the nonselective $\beta$-antagonist propranolol and the selective $\beta_{1}$-AR antagonist metoprolol both increased neurite outgrowth significantly in cultured sympathetic neurons, indicating direct growth-promoting effects on sympathetic neurons by $\beta_{1}$-AR inhibition. Support for the selectivity of this effect comes from the finding that blockade of $\beta_{2}$ receptors by ICI 118551 is ineffective in altering outgrowth. Interestingly, neuritogenic effects of both propranolol and metoprolol occurred only at the lower concentrations, which most closely approximate estimates of in vivo therapeutic concentrations of these drugs (Abrahamsson et al., 1990; Takahashi et al., 1993), and were lost when the concentration was increased 100 -fold. This may not be surprising, as both agents at high concentrations have membrane-stabilizing properties (Brunton et al., 2005), and membrane stabilization is known to inhibit axon outgrowth (Ibarretxe et al., 2007). 
Findings thus far led us to hypothesize that sympathetic neurons possess $\beta_{1}$-AR that negatively regulate axon outgrowth. Accordingly, we attempted to demonstrate the activity of these receptors by adding the $\beta_{1}$-agonist dobutamine to our cultures. However, despite using a wide range of concentrations, dobutamine had no effect on neurite outgrowth. Since sympathetic neurons display features that suggest that they continue to synthesize NE in vitro (Landis, 1978), we postulated that cultured neurons may be releasing NE in quantities sufficient to maximally activate $\beta_{1}$-ARs, such that additional ligand is ineffective. To test this hypothesis, we used the tyrosine hydroxylase inhibitor AMPT to prevent catecholamine biosynthesis. In cultures where NE synthesis was inhibited, neurite outgrowth was increased to an extent similar to that seen with $\beta$-AR blockade, indicating that NE synthesized in culture does indeed act to inhibit outgrowth. Now when dobutamine was added, outgrowth was reduced to that of control cultures with intact NE synthesis. Collectively, these studies indicate that, under normal culture conditions, NE tonically inhibits sympathetic neurite outgrowth via $\beta_{1}$-ARs. Consistent with this hypothesis, addition of dobutamine to cultures where NE synthesis is blocked suppressed outgrowth to levels typical of cultures in which NE is normally synthesized.

Aside from a role in modulating NE release, presynaptic $\beta_{1}$ ARs have not been implicated in influencing axonal outgrowth. However, there are several reports in other neural systems where transmitters do regulate axonal extension. For example, both dopamine and serotonin suppress elongation of axons in the Helisoma snail (Haydon et al., 1984; McCobb et al., 1988). At least some transmitter-mediated inhibition of axon growth appears to occur via autoreceptors, as serotonin inhibits outgrowth of serotoninergic axons from rat raphe neurons (Whitaker-Azmitia and Azmitia, 1986), and glutamate at high doses reduces axonal outgrowth by immobilizing growth cones of glutaminergic pyramidal neurons (Mattson et al., 1988). Thus, precedents exist for suggesting that sympathetic neurotransmitter autoreceptors could play a critical role in regulating axon outgrowth.

Although enhanced sympathetic outgrowth is likely to contribute to $\beta$-blocker withdrawal syndrome, it may be relevant to other pathophysiological situations as well. $\beta$-Blockers are commonly administered to patients with myocardial infarction because of their ability to reduce cardiac excitability, myocardial oxygen consumption, plasma angiotensin II (Ichihara et al., 1995), and sudden death (Hunt, 2005). However, heart failure is accompanied by diminished sympathetic innervation in nonnecrotic regions of the ventricle (Himura et al., 1993; Li et al., 2004), which could contribute to cardiac dysfunction. It is interesting to speculate that in heart failure patients, $\beta$-blocker therapy could prove beneficial not only by directly altering cardiac properties, but also by restoring cardiac sympathetic innervation. Our findings of normalization of axon numbers after propranolol infusion in the intact myocardium in this rat model of myocardial infarction suggest that this may be the case. Consistent with the idea that sympathetic axon density may be restored in the failing ventricle, ${ }^{123}$ I-metaiodobenzylguanidine scintigraphic studies in patients receiving $\beta$-blockers show increased ventricular catecholamine reuptake (Merlet et al., 1999; Toyama et al., 2003; Cohen-Solal et al., 2005). It is also of interest that, in our model, hyperinnervation induced by infarction was unaffected by propranolol administration. There is abundant evidence that myocardial ischemic injury is associated with proliferation of sympathetic axons in the vicinity of the infarct (Cao et al., 2000; Hasan et al., 2006; Wernli et al., 2009). Somewhat surprisingly, this hyperinnervation was not increased by $\beta$-blocker administration, a finding that may suggest an upper limit beyond which additional increases in innervation density are not apparent. On the other hand, it has been reported in rabbits that sympathetic hyperinnervation in the infarct border region is reduced by metoprolol (Jiang et al., 2007). Border region sprouting is likely to involve complex interactions among target-derived trophic factors, inflammatory cells, and damaged and regenerating axons, and response variability may not be surprising. Further studies are necessary to determine whether $\beta$-blockers alter postinfarct sympathetic innervation patterns in humans.

In summary, we propose that sympathetic neurons possess presynaptic $\beta_{1}$-ARs that, when activated by physiological levels of NE or other agonists, inhibit axon extension. We further hypothesize that this is an important mechanism for establishing levels of target innervation density. According to this concept, when innervation density is low, levels of NE will also be low and sympathetic axons will be encouraged to proliferate. This will continue until local levels of NE are sufficient to activate presynaptic $\beta_{1}$-ARs, at which point further axon extension would be prevented. Such a feedback system could provide a sensitive mechanism for establishing final levels of target innervation where the set point for innervation density is determined by the local concentration of transmitter. In the presence of a drug that blocks $\beta_{1}$-ARs, outgrowth inhibition is lost and target organ innervation density is therefore increased.

\section{References}

Aarons RD, Nies AS, Gal J, Hegstrand LR, Molinoff PB (1980) Elevation of beta-adrenergic receptor density in human lymphocytes after propranolol administration. J Clin Invest 65:949-957.

Ablad B, Borg KO, Carlsson E, Ek L, Johnson G, Malmfors T, Regardh CG (1975) A survey of the pharmacological properties of metoprolol in animals and man. Acta Pharmacol Toxicol (Copenh) 36 [Suppl 5]:7-23.

Abrahamsson B, Lücker P, Olofsson B, Regårdh CG, Sandberg A, Wieselgren I, Bergstrand R (1990) The relationship between metoprolol plasma concentration and beta 1-blockade in healthy subjects: a study on conventional metoprolol and metoprolol CR/ZOK formulations. J Clin Pharmacol 30:S46-S54.

Brunton L, Lazo J, Parker K (2005) Goodman and Gilman's the pharmacological basis of therapeutics. New York: McGraw-Hill.

Butler CK, Smith FM, Nicholson J, Armour JA (1990) Cardiac effects induced by chemically activated neurons in canine intrathoracic ganglia. Am J Physiol 259:H1108-H1117.

Cao JM, Fishbein MC, Han JB, Lai WW, Lai AC, Wu TJ, Czer L, Wolf PL, Denton TA, Shintaku IP, Chen PS, Chen LS (2000) Relationship between regional cardiac hyperinnervation and ventricular arrhythmia. Circulation 101:1960-1969.

Chakrabarty A, Blacklock A, Svojanovsky S, Smith PG (2008) Estrogen elicits dorsal root ganglion axon sprouting via a renin-angiotensin system. Endocrinology 149:3452-3460.

Cohen-Solal A, Rouzet F, Berdeaux A, Le Guludec D, Abergel E, Syrota A, Merlet P (2005) Effects of carvedilol on myocardial sympathetic innervation in patients with chronic heart failure. J Nucl Med 46:1796-1803.

Colangelo AM, Follesa P, Mocchetti I (1998) Differential induction of nerve growth factor and basic fibroblast growth factor mRNA in neonatal and aged rat brain. Brain Res Mol Brain Res 53:218-225.

Conlon D, Johnston A, Turner P, O’Malley K, Kilfeather S (1991) Hepatic beta-adrenoceptor adaptation during propranolol administration is impaired in aging rats. Eur J Pharmacol 208:323-330.

Dal Toso R, De Bernardi MA, Costa E, Mocchetti I (1987) Beta-adrenergic receptor regulation of NGF-mRNA content in rat C6-2B glioma cells. Neuropharmacology 26:1783-1786.

Deegan R, He HB, Krivoruk Y, Wood AJ, Wood M (1995) Regulation of norepinephrine release by beta 2 -adrenergic receptors during halothane anesthesia. Anesthesiology 82:1417-1425.

DiBona GF, Sawin LL (1999) Effect of metoprolol administration on renal sodium handling in experimental congestive heart failure. Circulation 100:82-86. 
Dollery CT, Maling TJ (1979) Beta-blocker withdrawal syndrome. Br Med J 2:1074-1075.

Germino FW (2009) The management and treatment of hypertension. Clin Cornerstone 9 [Suppl 3]:S27-S33.

Harrison DC, Alderman EL (1976) Editorial: Discontinuation of propranolol therapy: cause of rebound angina pectoris and acute coronary events. Chest 69:1-2.

Hasan W, Jama A, Donohue T, Wernli G, Onyszchuk G, Al-Hafez B, Bilgen M, Smith PG (2006) Sympathetic hyperinnervation and inflammatory cell NGF synthesis following myocardial infarction in rats. Brain Res 1124:142-154.

Haydon PG, McCobb DP, Kater SB (1984) Serotonin selectively inhibits growth cone motility and synaptogenesis of specific identified neurons. Science 226:561-564.

Hedberg A, Isaksson O, Lundgren B (1980) Sustained cardiac beta adrenoceptor blockade in vitro and increased vulnerability to aconitine-induced arrhythmias in vivo after propranolol withdrawal in rats. J Pharmacol Exp Ther 214:664-669.

Heilbrunn SM, Shah P, Bristow MR, Valantine HA, Ginsburg R, Fowler MB (1989) Increased beta-receptor density and improved hemodynamic response to catecholamine stimulation during long-term metoprolol therapy in heart failure from dilated cardiomyopathy. Circulation 79:483-490.

Himura Y, Felten SY, Kashiki M, Lewandowski TJ, Delehanty JM, Liang CS (1993) Cardiac noradrenergic nerve terminal abnormalities in dogs with experimental congestive heart failure. Circulation 88:1299-1309.

Hoeks SE, Scholte Op Reimer WJ, van Urk H, Jörning PJ, Boersma E, Simoons ML, Bax JJ, Poldermans D (2007) Increase of 1-year mortality after perioperative beta-blocker withdrawal in endovascular and vascular surgery patients. Eur J Vasc Endovasc Surg 33:13-19.

Hunt SA (2005) ACC/AHA 2005 guideline update for the diagnosis and management of chronic heart failure in the adult: a report of the American College of Cardiology/American Heart Association Task Force on Practice Guidelines (Writing Committee to Update the 2001 Guidelines for the Evaluation and Management of Heart Failure). J Am Coll Cardiol 46:e1-82.

Ibarretxe G, Perrais D, Jaskolski F, Vimeney A, Mulle C (2007) Fast regulation of axonal growth cone motility by electrical activity. J Neurosci 27:7684-7695.

Ichihara A, Suzuki H, Murakami M, Naitoh M, Matsumoto A, Saruta T (1995) Interactions between angiotensin II and norepinephrine on renin release by juxtaglomerular cells. Eur J Endocrinol 133:569-577.

Jiang H, Lu Z, Yu Y, Zhao D, Jian X, Yang B, Huang C (2007) Effects of metoprolol on sympathetic remodeling and electrical remodeling at infarcted border zone after myocardial infarction in rabbits. Cardiology 108:176-182.

Kaye DM, Vaddadi G, Gruskin SL, Du XJ, Esler MD (2000) Reduced myocardial nerve growth factor expression in human and experimental heart failure. Circ Res 86:E80-E84.

Kondo M, Fujiwara T, Tabei R (1996) Noradrenergic hyperinnervation in the heart of stroke-prone spontaneously hypertensive rats (SHRSP). Hypertens Res 19:69-73.

Landis SC (1978) Growth cones of cultured sympathetic neurons contain adrenergic vesicles. J Cell Biol 78:R8-R14.

Lefkowitz RJ (2004) Historical review: a brief history and personal retrospective of seven-transmembrane receptors. Trends Pharmacol Sci 25:413-422.

Li W, Knowlton D, Van Winkle DM, Habecker BA (2004) Infarction alters both the distribution and noradrenergic properties of cardiac sympathetic neurons. Am J Physiol Heart Circ Physiol 286:H2229-H2236.

Mattson MP, Dou P, Kater SB (1988) Outgrowth-regulating actions of glutamate in isolated hippocampal pyramidal neurons. J Neurosci 8:2087-2100

McCobb DP, Haydon PG, Kater SB (1988) Dopamine and serotonin inhibition of neurite elongation of different identified neurons. J Neurosci Res 19:19-26.

Merlet P, Pouillart F, Dubois-Randé JL, Delahaye N, Fumey R, Castaigne A, Syrota A (1999) Sympathetic nerve alterations assessed with 123I-MIBG in the failing human heart. J Nucl Med 40:224-231.

Miller RR, Olson HG, Amsterdam EA, Mason DT (1975) Propranololwithdrawal rebound phenomenon. Exacerbation of coronary events after abrupt cessation of antianginal therapy. N Engl J Med 293:416-418.

Nattel S, Rangno RE, Van Loon G (1979) Mechanism of propranolol withdrawal phenomena. Circulation 59:1158-1164.

Pacher P, Nagayama T, Mukhopadhyay P, Bátkai S, Kass DA (2008) Measurement of cardiac function using pressure-volume conductance catheter technique in mice and rats. Nat Protoc 3:1422-1434.

Rodriguez-Ospina L, Montano-Soto L (2008) Management of chronic stable angina pectoris. Bol Asoc Med P R 100:39-47.

Scott TM, Pang SC (1983) The correlation between the development of sympathetic innervation and the development of medial hypertrophy in jejunal arteries in normotensive and spontaneously hypertensive rats. J Auton Nerv Syst 8:25-32.

Steinle JJ, Smith PG (2002) Role of adrenergic receptors in vascular remodelling of the rat choroid. Br J Pharmacol 136:730-734.

Takahashi H, Ogata H, Kashiwada K, Ohira M, Someya K (1993) Dosing rate-dependent relationship between propranolol plasma concentration and beta-blockade. J Pharmacol Exp Ther 265:681-689.

Toyama T, Hoshizaki H, Seki R, Isobe N, Adachi H, Naito S, Oshima S, Taniguchi K (2003) Efficacy of carvedilol treatment on cardiac function and cardiac sympathetic nerve activity in patients with dilated cardiomyopathy: comparison with metoprolol therapy. J Nucl Med 44:1604-1611.

Vincent GM, Schwartz PJ, Denjoy I, Swan H, Bithell C, Spazzolini C, Crotti L, Piippo K, Lupoglazoff JM, Villain E, Priori SG, Napolitano C, Zhang L (2009) High efficacy of beta-blockers in long-QT syndrome type 1: contribution of noncompliance and QT-prolonging drugs to the occurrence of beta-blocker treatment "failures." Circulation 119:215-221.

Viskin S, Kitzis I, Lev E, Zak Z, Heller K, Villa Y, Zajarias A, Laniado S, Belhassen B (1995) Treatment with beta-adrenergic blocking agents after myocardial infarction: from randomized trials to clinical practice. J Am Coll Cardiol 25:1327-1332.

Wang W, Zhu W, Wang S, Yang D, Crow MT, Xiao RP, Cheng H (2004) Sustained betal-adrenergic stimulation modulates cardiac contractility by Ca2+/calmodulin kinase signaling pathway. Circ Res 95:798-806.

Watson-Wright W, Boudreau G, Cardinal R, Armour JA (1991) Beta 1- and beta 2-adrenoceptor subtypes in canine intrathoracic efferent sympathetic nervous system regulating the heart. Am J Physiol 261:R1269R1275.

Wernli G, Hasan W, Bhattacherjee A, van Rooijen N, Smith PG (2009) Macrophage depletion suppresses sympathetic hyperinnervation following myocardial infarction. Basic Res Cardiol 104:681-693.

Whitaker-Azmitia PM, Azmitia EC (1986) Autoregulation of fetal serotonergic neuronal development: role of high affinity serotonin receptors. Neurosci Lett 67:307-312.

Yusuf S, Peto R, Lewis J, Collins R, Sleight P (1985) Beta blockade during and after myocardial infarction: an overview of the randomized trials. Prog Cardiovasc Dis 27:335-371. 